Закономерности развития региональных агропродовольственных систем: материалы Всероссийской школы молодых ученых. - Саратов: Изд-во ИАгП РАН, 2017. - С. 28-33.

7. Система таблиц «Затраты - Выпуск» России за 2003 год: стат. сб. / Росстат. - М., 2006. - 116 с.

8. Таблицы ресурсов и использования товаров и услуг за 2012-2015 гг. / Росстат. - Режим доступа: http://www.gks.ru/wps/wcm/connect/rosstat_main/ rosstat/ru/statistics/accounts/\#.

9. Федеральная научно-техническая программа развития сельского хозяйства на 2017-2025 годы / Консультант плюс. - Режим доступа: http://www.consultant. $\mathrm{ru} /$ document/cons_doc_LAW_223631.
10. National Input-Output Tables, Relaesed November 2016. - URL: http://www.wiod.org/new_site/database/niots.htm .

Потапов Андрей Павлович, канд. экон. наук, доцуен, ведущий научный сотрудник лаборатории инновационного развития производственного потенциила агропромышленного комплекса, Федеральное государственное бюджетное учреждение науки Институт аграрных проблем Российской академии наук. Россия.

410012, г. Саратов, ул. Московская, 94.

Тел.: (8452) 26-35-89; e-mail: app2008@yandex.ru.

Ключевые слова: ресурсный потенциал; аграрное производство; затраты ресурсов; ресурсоемкость продукции; таблищзы «Затраты - Выпуск».

\title{
ESTIMATION OF DYNAMICS OF RESOURCE EXPENDITURE AND RESOURCE INTENSITY OF AGRARIAN MANUFACTURE OF RUSSIA
}

Potapov Andrey Pavlovich, Candidate of Economic Sciences, Associate Professor, Leading Researcher of the Laboratory of innovative development of production potential of agro-industrial complex, Federal State Budgetary Science Institution Institute of Agrarian Problems of Russian Academy of Sciences.

Keywords: resource potential; agrarian manufacture; expenditure of resources; resource intensity of production; tables «InputOutput»

In the article dynamics of resource expenditure and resource intensity of agrarian production in Russia is inves- tigated. With use of data of international research project World Input-Output Database (WIOD) the analysis of level and structure of expenditure of the basic industrial resources in agrarian sphere is lead. Influence of dynamics of use of labour, ground and material resources on gross output of agriculture, also crop and animal industries and a grain husbandry is estimated. The author concludes that influence of quantitative characteristics of resource potential on production in agriculture has different character that has been connected with change of qualitative characteristics and intensity of use of every kind of resources.

\section{УПРАВЛЕНИЕ ЭКОНОМИЧЕСКОЙ УСТОЙЧИВОСТЬЮ ПРЕДПРИЯТИЙ МЯСНОЙ ПРОМЫШЛЕННОСТИ НА ОСНОВЕ МАРКЕТИНГОВОЙ ЛОГИСТИКИ}

\author{
РОдИОНОВА Ирина Анатольевна, Саратовский государственный аграрный университет \\ имени Н.И. Вавилова
}

дудникОВА Елена Борисовна, Саратовский государственный аграрный университет имени Н.И. Вавилова. Россия.

ЯКУШЕВА Вероника Викторовна, Саратовский государственный технический университет им. Гагарина Ю.А.

В статье обоснованы направления повышения экономической устойчивости предприятий мясной промышленности регионального АПК на основе АВС-анализа. Установлено, ито в настоящее время стратегия роста мясоперерабатывающих предприятий утрачивает свою актуальность. Это обусловлено снижением жизненного уровня населения, ростом иен на мясную продукиию и усилением конкуренции со стороны производителей. Выявлено, что экономическая устойчивость предприятий приобретает системный характер и связана с применением стратегии дифференциации, опираюшуюся на маркетинговое ноу-хау компании, ее превосходство в выявлении и удовлетворении ожиданий покупателей. Наиболее полно отразить требования рынка помогает АВС-анализ, использование которого позволяет предприятиям повысить эффективность функционирования за сиет оптимизации ассортиментного портфеля.

Введение. Мясная промышленность является одной из отраслей, обеспечивающих продовольственную безопасность и независимость страны. По данным Федеральной службы государственной статистики РФ [8], удельный вес предприятий, занятых в мясной отрасли, в сред- нем по стране составляет 60,0-65,0 \% от общего числа предприятий пищевой промышленности, при этом более 80,0 \% объема произведенной ими продукции поставляется на внутренний потребительский рынок.

В начале 90-х гг. ХХ в. приоритетной зада- 
чей мясоперерабатывающих предприятий была выживаемость в условиях рыночной трансформации, в настоящее время акценты смещены в сторону обеспечения устойчивости их развития. Так, за 2010-2016 гг. производство мяса и субпродуктов пищевых убойных животных в Российской Федерации выросло в 2,18 раза, или на 1408 тыс. т, полуфабрикатов мясных (мясосодержащих) на 62,3 \%, или на 692 тыс. т, стабилизировалось производство колбасных изделий и консервов. В современных экономических исследованиях проблема устойчивости рассматривается шире рамок антикризисного управления, поскольку ее рассматривают как дополнительную детерминанту повышения эффективности производства в целом.

На развитие отрасли большое влияние оказывают факторы внешней среды, что делает предприятия уязвимыми при наступлении кризисных ситуаций [1]. Ключевыми проблемами, снижающими экономическую устойчивость мясной промышленности, остаются: дефицит сырья; отсутствие современной системы контроля качества и безопасности продукции на этапах переработки, транспортировки и хранения; недостаточное использование в производстве технологий замкнутого цикла с более эффективной выработкой продукта, предполагающих сокращение потерь сырья; высокая зависимость отрасли от импортного оборудования.

Цель исследования является обоснование направлений повышения экономической устойчивости предприятий мясной промышленности на основе маркетинговой логистики.

Методика исследований. Управление промышленным ассортиментом является одним из основных востребованных направлений повышения экономической устойчивости предприятия. Для анализа взаимодействия маркетинга и логистики нами было использовано понятие маркетингового и логического микса.

В маркетинге - это совокупность четырех $\ll P »$ :

product (продукт);

price (цена); лий);

place (место приложения коммерческих уси-

promotion (система продвижения продукта).

В логистике - это совокупность семи $\ll R \gg:$

right product (продукт);

right guantity (количество продукта);

right condition (качество продукта);

right place (территория распространения продукта);

right time (временные затраты на работу с продуктом);

rght customer (наличие заказчиков продукта);

right cost (рассчитанные затраты на работу с продуктом) [6].
Одной из основных областей функционального взаимодействия логистики и маркетинга является формирование ассортиментной политики предприятия. С позиций маркетинг-логистической стратегии ассортиментная политика представляет собой процесс воздействия на производство и рынок для достижения соответствия структуры ассортимента выпускаемой продукции структуре платежеспособного спроса. Цель ассортиментной политики - соориентировать предприятие на выпуск товаров, наиболее соответствующих спросу конкретных покупателей, а также обеспечить эффективное использование сырьевых, технологических и финансовых ресурсов [7].

Авторами, на примере 000 «Дымок» г. Энгельса, были использованы функциональные возможности продукта «1С: Предприятие 8.0. Мясокомбинат» для подсистемы «Управление отношениями с покупателями и поставщиками» для проведения интегрированного $A B C$-анализа отношений с клиентами, что позволило сегментировать покупателей на классы в зависимости от доли клиента в выручке и прибыли предприятия: важные (A-класс), приносящие $50,0 \%$ результата, средней важности ( $B$-класс), приносящие еще $30,0 \%$ результата, низкой важности ( $C$-класс), которые приносят еще 20,0 \% результата.

$\mathrm{B}$ основе управления ассортиментом $A B C$ анализа положен регулирующий принцип Парето. Согласно установившемуся мнению, закон Парето (принцип Парето принцип 20/80) - это эмпирическое правило, названное в честь экономиста и социолога Вильфредо Парето, которое в наиболее общем виде формулируется следующим образом: «20 \% усилий дают 80 \% результата, а остальные 80 \% усилий - лишь $20 \%$ результата». Он широко используется как базовая установка в анализе факторов эффективности какой-либо деятельности и оптимизации ее результатов.

Результаты исследований. В настоящее время многие предприятия мясной промышленности имеют широкий ассортимент продукции. В исследуемом предприятии он превышает 110 товарных позиций. Однако перенасыщение товарного ассортимента ведет к сокращению общей прибыли, так как товары начинают конкурировать друг с другом, т.е. наблюдается эффект «каннибализма» товаров. Поэтому, по нашему мнению, столь важен продуманный подход к проблеме оптимизации ассортимента (рис. 1).

Данные по производству и реализации товаров могут указать на продукты, которые необходимо исключить из производственной программы вследствие их малой доли реализации или убыточности. По мнению генерального директора отраслевого агентства «ВАТЕЛЬ МАРКЕТИНГ» Р.Г. Калинина, на предприятиях сло- 


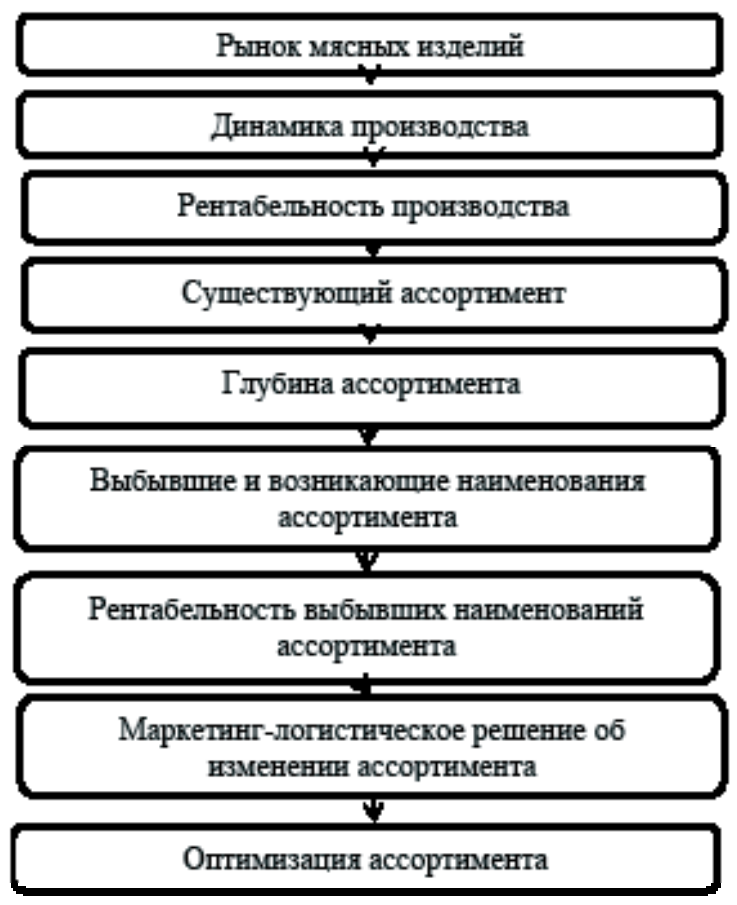

Рис. 1. Маркетинг-логистическая стратегия управления ассортиментом мясных изделий

жилась пагубная привычка производить продукт любым, самым маленьким объемом под девизом: «раз есть спрос - мы должны его удовлетворить». Задача предприятия - производить большими объемами качественный продукт и предлагать его по привлекательной цене [4].

Негативными факторами раздутого ассортиментного портфеля являются:

рост складских запасов и упаковки;

нестабильность качества, так как предприятие не может делать качественный продукт минимальными объемами;

высокая себестоимость единицы продукции, связанная с частыми переходами не целиком загруженных смен, и обычно, большой доле ручного труда;

широкий ассортимент, раздувающий фокус внимания у торговых представителей, что ведет к ослаблению возможностей по эффективному продвижению продукции.

Идеальный продуктовый портфель для мясоперерабатывающих предприятий должен удовлетворять следующим требованиям:

максимально учитывать потребности населения региона;

быть ориентированным на новые потребительские предпочтения;

приносить прибыль стейкхолдерам;

увеличивать маржинальный доход;

быть удобным в управлении службой продаж;

позволять максимально загрузить производственные мощности.

На рис. 2. показана ассортиментная структура продукции предприятия по стоимости реализованной продукции в динамике. Наибольший удельный вес в структуре реализованной про-

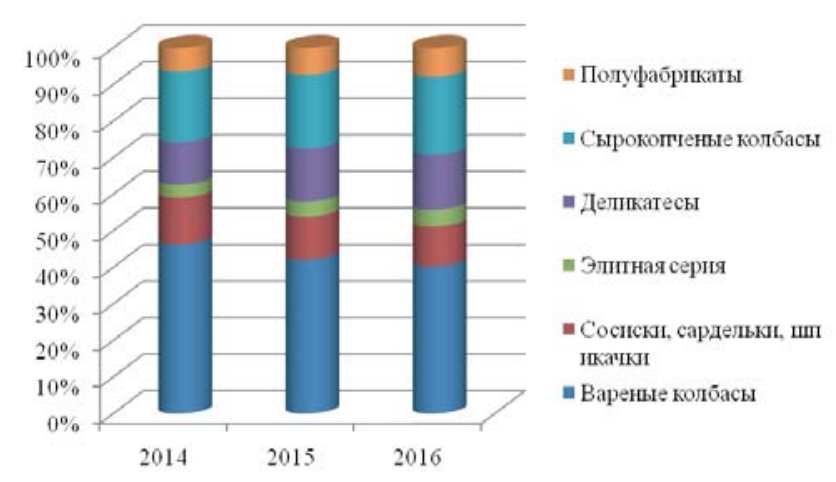

Рис. 2. Динамика структуры стоимости реализованной предприятия по годам, \%

дукции 2014 г. приходился на вареные 46,3 \% и сырокопченые 19,3 \% колбасы. Заметный вклад в доход предприятия был получен от реализации сосисек, сарделей - 12,8 \%. Вареные колбасы как наиболее дешевый сегмент продолжают составлять самую значительную долю объема реализации предприятия, однако наметилась тенденция к их снижению.

За три анализируемых года удельный вес вареных колбас в структуре реализованной продукции сократился на 11,92 п.п. На предприятии производят 9 видов вареных колбас, большая часть которых изготавливается по ГОСТу. Например, наибольший объем продаж составляют вареные колбасы массой 1,3 кг, в то время как весовая категория 0,45 кг пользуется меньшей популярности у потребителя. Основу продаж составляют группы вареных и сырокопченых колбас, деликатесы, на которые в 2016 г. приходилось 84,1 \% прибыли.

Проведенный $A B C$-анализ показал следующие результаты (табл. 1).

К категории $A$ отнесена группа вареных колбас, а также сырокопченые колбасы. Несмотря на снижение реальных доходов населения и рост цен, данный сегмент прочно занимает свои позиции в объеме реализованной продукции предприятия.

К категории В отнесена группа «Деликатесы», так как объемы реализации по этой группе увеличиваются, а группа «Сосиски, сардели, шпикачки» из категории $B$ перешли в категорию $C$ из-за снижения темпов продажи.

Деликатесная группа упрочивает свои позиции из-за расширения номенклатуры. Упор делается на производстве деликатесов из мяса птицы и свинины как наиболее дешевых видов сырья. Данная стратегия предприятия оправдана, так как приносит хорошую прибыль. В то же время ассортиментная линейка слишком глубокая и включает в себя более 25 наименований продукции, отдельные виды которой являются убыточными для предприятия, например, «Рулет забава», «Зельц деревенский». Следует отказаться от их производства в пользу более рентабельных видов продукции. 
АВС-анализ номенклатуры произведенной и реализованной продукции 000 «Дымок» 3а 2014-2016 гг.

\begin{tabular}{|c|c|c|c|c|c|c|c|c|c|}
\hline \multirow[t]{2}{*}{ Ассортиментная группа } & \multicolumn{3}{|c|}{ Группа $A B C$-анализа } & \multicolumn{3}{|c|}{$\begin{array}{c}\text { Удельный вес в стоимости } \\
\text { реализованной продукции, } \\
\%\end{array}$} & \multicolumn{3}{|c|}{$\begin{array}{c}\text { Удельный вес в общем } \\
\text { объеме прибыли, \% }\end{array}$} \\
\hline & 2014 г. & 2015 г. & 2016 г. & 2014 г. & 2015 г. & 2016 г. & 2014 г. & 2015 г. & 2016 г. \\
\hline Вареные колбасы & $A$ & $A$ & $A$ & 46,3 & 42,1 & 40,3 & 35,4 & 36,5 & 35,3 \\
\hline $\begin{array}{l}\text { Сосиски, сардели, шпи- } \\
\text { качки }\end{array}$ & $B$ & C & C & 12,8 & 11,8 & 10,9 & 7,1 & 6,9 & 6,4 \\
\hline Элитная серия & $C$ & $C$ & $C$ & 3,5 & 4,1 & 4,6 & 0,7 & 0,5 & 0,4 \\
\hline Деликатесы & $\mathrm{C}$ & $B$ & $B$ & 11,6 & 14,5 & 15,0 & 20,3 & 20,2 & 21,3 \\
\hline Сырокопченые колбасы & $B$ & $A$ & $A$ & 19,3 & 20,2 & 21,3 & 28,3 & 26,9 & 27,5 \\
\hline Полуфабрикаты & $C$ & $C$ & $C$ & 6,5 & 7,3 & 7,9 & 8,2 & 9,0 & 9,1 \\
\hline
\end{tabular}

Элитная серия отнесена к категории С. Предприятие производит только один вид - «Московская элитная» по ГОСТу весом 0,5 и 1,0 кг. Объемы производства данного вида продукции незначительны, но из-за высокой цены рентабельность производства высокая.

Предприятие также производит полуфабрикаты, большая часть которых приходится на пельмени и вареники. Рынок пельменей остается достаточно перспективным, он растет как в стоимостном, так и натуральном выражении. Производители стараются разнообразить ассортимент, например, производят пельмени ручной лепки (по цене они дороже, но и мяса в них больше - 50-70 \% в готовом изделии по сравнению с 30 \% при автоматизированном изготовлении).

Рынок мясных полуфабрикатов характеризуется низкой концентрацией, так как на нем оперируют крупные, средние и мелкие фирмы. Из-за относительной легкости производства мясных полуфабрикатов возникает высокая конкуренция, что требует усиления внимания к качеству и цене. На анализируемом предприятии производят фарш домашний, перец фаршированный и чебуреки. Данные виды продукции отнесены к категории С, так как являются убыточными и занимают малую долю в объеме производства.

Таким образом, наиболее перспективным направлением на исследуемом предприятии следует считать производство вареных и сырокопченых колбас, а также деликатесов.

На рис. 3 представлены данные, характеризующие глубину ассортимента мясных изделий в раз- резе основных товарных групп. Наиболее глубокий ассортимент характерен для деликатесов (20), полуфабрикатов (12) и вареных колбас (9).

Авторами был проведен углубленный $A B C$ анализ по вареным колбасам, так как данная категория является основной в объеме производства. Как видно из рис. 4 к категории $A$ из 17 ассортиментных позиций можно отнести только: «Докторскую» ГОСТ, вес 1,3 кг; «Любительскую» ГОСТ, вес 1,3 кг; «Молочную» ГОСТ, вес 1,3 кг; «Докторскую» ГОСТ, вес 0,450; объем реализации которых составляет 60,8 \%. К категории $B-$ «Русскую» ГОСТ, вес 1,3 кг; «Молочную» ГОСТ, вес 1,3 кг; «Любительскую» ГОСТ, вес 0,450 кг; так как они приносят еще 21,3 \% выручки предприятия, и к категории $C$ все остальные.

Аналогичная ситуация прослеживается и по другим ассортиментным группам.

На протяжении анализируемого периода выбыло 17 наименований мясных изделий, а введено - 22, то есть около 15,0 \% ассортимента подверглось изменению. Данная ротация ассортимента является положительным явлением только в том случае, когда выбывающие наименования не рентабельны. Однако выбывающие наименования мясных изделий не были убыточными (рис. 5).

Таким образом, отсутствие системной маркетинг-логистической стратегии на предприятии привело к перераспределению ассортимента мясных изделий в пользу производства более дешевой, но менее доходной продукции, что снизило общую рентабельность производства.

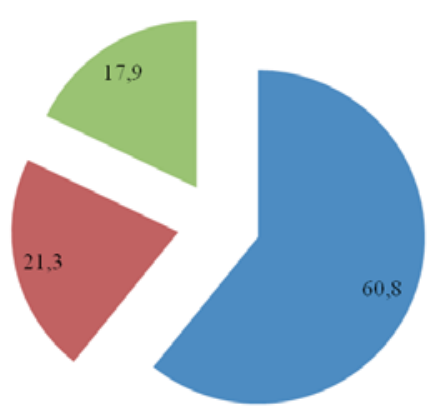

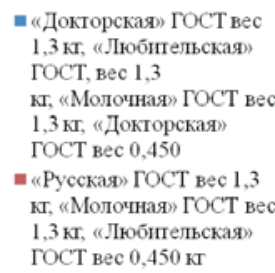




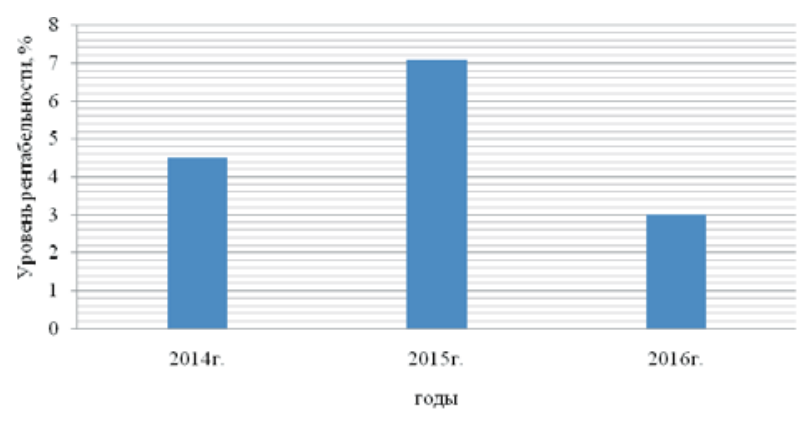

Рис. 5. Средняя рентабельность выбывших наименований мясных изделий, \%

В среднесрочной перспективе предприятию необходимо усилить позиции в наиболее прибыльных сегментах. Для этого необходимо, с одной стороны, сократить производство вареных колбас, отнесенных к категории $C$, а с другой, разработать эффективную маркетинговую политику. Необходимо констатировать, что в период насыщения потребительского рынка массовый маркетинг постепенно переходит в состояние сегментированного, т.е. строго ориентированного на запросы определенных потребительских групп [2].

Представленная на предприятии ассортиментная линейка вареных колбас имеет общие, характерные для данных изделий свойств и мало чем отличается от продукции конкурентов. Современные требования диктуют необходимость дифференцировать продукцию не только по органолептическим показателям, составу, стоимости, составу рецептур, виду оболочки, но и по ряду других приоритетных признаков. Среди важнейших необходимо выделить: уровень калорийности; ограниченное применение пищевых добавок, имеющих индексы $E$; повышенный уровень биологической ценности. То есть необходимо переходить от производства массовой обезличенной продукции к производству индивидуализирован- ных продуктов питания, например, такие раскрученные бренды как «Чистая этикетка» и «Здоровое пищеварение». Продукция данного сегмента выгодно отличается от конкурентов и формирует стратегические преимущества в сознании потребителя [5].

Специалисты датской Бизнес-школы Орехуса считают, что на мировом мясном рынке происходит переход проблем, связанных с производством и потреблением мяса из потребительском плоскости в плоскость гражданскую [2]. Производители мясной продукции в условиях кризиса испытывают давление со стороны конкурентов, экологов, вегетарианцев, массированных атак СМИ, поэтому должны использовать принципиально новые формы связей с потребителями:

устанавливать и поддерживать долгосрочные связи с потребителем;

обеспечивать укрепление степени доверия у потребителя к качеству и уровню безопасности предлагаемых промышленностью пищевых продуктов;

расширять представление населения о мясе, способах его производства и переработке; повышать осведомленность потребителей об уникальности состава мяса и медико-биологической ценности мясопродуктов в системе рационального питания;

показывать некомпетентность и предвзятость ряда утверждений и фактов, используемых масс-медиа в кампании против производителей пищевых продуктов;

обосновывать причины постоянно происходящего повышения цен на мясные продукты и т.д.

По прогнозам экспертов, доля крупных компаний будет расти, сильные бренды вытеснят слабые торговые марки. Следовательно, успешное управление брендами компании не только Таблица 2

Оптимальный ассортимент мясных изделий 000 «Дымок»

\begin{tabular}{|c|c|c|c|c|}
\hline \multirow[b]{2}{*}{ Показатель } & \multicolumn{2}{|c|}{ Товарные группы } & \multicolumn{2}{|c|}{ Удельный вес в объеме прибыли, \% } \\
\hline & $\begin{array}{c}\text { фактически в } \\
2016 \text { г. } \\
\end{array}$ & $\begin{array}{c}\text { оптимальный } \\
\text { ассортимент }\end{array}$ & $\begin{array}{c}\text { фактически в } \\
2016 \text { г. } \\
\end{array}$ & $\begin{array}{l}\text { оптимальный } \\
\text { ассортимент }\end{array}$ \\
\hline Вареные колбасы & 9 & 7 & 35,3 & 36,1 \\
\hline Сосиски, сардели, шпикачки & 13 & 5 & 6,4 & 3,8 \\
\hline Элитная серия & 2 & - & 0,4 & - \\
\hline Деликатесы & 25 & 17 & 21,3 & 24,7 \\
\hline Сырокопченые колбасы & 11 & 9 & 27,5 & 30,5 \\
\hline Полуфабрикаты & 12 & 5 & 9,1 & 4,9 \\
\hline Количество товарных позиций & 72 & 43 & 100,0 & 100,0 \\
\hline \multicolumn{3}{|c|}{ Прибыль (убыток от продаж), тыс. руб. } & 3232 & 4489 \\
\hline \multicolumn{3}{|l|}{ Рентабельность продаж, \% } & 4,41 & 8,13 \\
\hline
\end{tabular}


позволит повысить ее конкурентоспособность, обеспечить приверженность и лояльность потребителей продукции, но и повысит их экономическую устойчивость [4].

В то же время существуют определенные проблемы, влияющие на проведение эффективной маркетинговой политики, в то числе и брендирования российских предприятий мясной промышленности, среди которых высочайшая насыщенность российского рынка пищевой промышленности брендами; отсутствие эффективной государственной системы контроля качества и сертификации продукции пищевой промышленности, что в некоторых случаях приводит к формированию неверных ассоциаций о продуктах компании у потребителей; этическая проблема брендинга; наличие, в основном, управления брендами отдельных продуктов, а не брендом предприятия в целом.

Заключение. На основании проведенных расчетов нами был обоснован оптимальный ассортимент мясных изделий ООО «Дымок» (табл. 2).

Таким образом, проведенный $A B C$-анализ показал, что предприятию необходимо сократить с 72 до 43 товарные группы. Основой оптимального ассортимента будет производство вареных колбас, удельный вес прибыли которых составит $36,1 \%$, деликатесов - 24,7 \% и сырокопченых колбас - 30,5 \%. К вопросу об удалении или существенном снижении продуктов из производственной программы организации необходимо подходить с осторожностью, так как постоянные затраты, падающие на долю продукции, исключенную из ассортимента, перейдут на оставшуюся, тем самым снизив их рентабельность. Следовательно, организации необходимо проводить гибкую товарную политику, планирование, учет затрат и прибыли.

\section{СПИСОК ЛИТЕРАТУРЫ}

1. Васькова Ю.И., Глебов И.П. Основные направления развития антикризисного направления мясоперерабатывающими предприятиями АПК // Аграр- ный научный журнал. - 2017. - № 11. - С. 76-78.

2. Жаринов А.И., Морозов А.В. Социально-экономические факторы и ассортиментная политика мясоперерабатывающих предприятий // Мясная индустрия. - 2015. - № 10. - С. 8-13.

3. Калинин Р.Г. Рост прибыли мясоперерабатывающего производства: конкретные шаги // Всё о мясе. - 2015. - № 1. - С. 40-43.

4. Родина Е.А. Брендинг как инструмент развития российского рынка пищевой промышленности // Казанский экономический вестник. - 2014. № $2(10)$. - С. $82-89$.

5. Родионова И.А., Якушева В.В. Влияние сырьевого обеспечения на устойчивость производственной деятельности региональных предприятий мясной промышленности // Научное обозрение: теория и практика. - 2017. - № 5. - С. 92-101.

6. Осипова Л.В. Основы коммерческой деятельности: учебник для вузов. -М.: ЮНИТИ-ДАНА, 2000. $623 \mathrm{c}$.

7. Фатьянов С.О., Чутков К.А. Стратегии в маркетинге и логистике, их взаимосвязь // Новые технологии в науке, образовании, производстве: сб. науч. тр. по материалам Междунар. науч.-практ. конф. - Рязань, 2014. - С. 355-366.

8. Федеральная служба государственной статистики РФ. - Режим доступа: gks.ru.

Родионова Ирина Анатольевна, $\partial-p$ экон. наук, проф. кафедры «Организация производства и управление бизнесом в АПК», Саратовский государственный аграрный университет имени Н.И. Вавилова; старший научный сотрудник ФГБНУ «Поволжский научно-исследовательский институт экономики и организации АПК». Россия.

410012, г. Саратов, Театральная пл., 1.

Тел.: (8452) 26-27-83.

Дудникова Елена Борисовна, $\partial$ - $p$ социол. наук, проф. кафедры «Социально-правовые и гуманитарно-педагогические науки», Саратовский государственный аграрный университет имени Н.И. Вавилова. Россия.

410012, г. Саратов, Театральная пл., 1.

Тел.: (8452) 26-27-83.

Якушева Вероника Викторовна, заведующая отделением СПО ИРБиС, Саратовский государственный технический университет им. Гагарина Ю.А. Россия.

410028, г. Саратов, ул. Горького, д. 9.

Тел.: (8452) 39-30-30.

Ключевые слова: экономическая устойчивость; маркетинговая логистика; мясная промышленность.

\section{MANAGEMENT OF ECONOMIC STABILITY OF THE ENTERPRISES OF THE MEAT INDUSTRY ON THE BASIS OF MARKETING LOGISTICS}

Rodionova Irina Anatolyevna. Doctor of Economic Sciences, Associate Professor of the chair "Organization of Production and Business Management in AIC", Saratov State Agrarian University named after N.I. Vavilov;

Dudnikova Elena Borisovna, Doctor of Sociological Sciences, Professor of the chair "Socio-legal and Humanitarian-pedagogical Sciences", Saratov State Agrarian University named after N.I. Vavilov. Russia.

Yakusheva Veronika Viktorovna, Manager of office SPE, Saratov State Technical University named after Gagarin Y.A. Russia. dustry.

Keywords: economic stability; marketing logistics; meat in-
In article the directions of increase in economic stability of the enterprises of the meat industry of regional agrarian and industrial complex on the basis of ABC analysis are proved. It is established that now the strategy of growth of the meat-processing enterprises loses the relevance. It is caused by decline in living standards of the population, increase in prices for meat production and strengthening of the competition from producers. It is revealed that economic stability of the enterprises gains system character and it is connected with application of strategy of differentiation, leaning on a marketing know-how of the company, her superiority in identification and satisfaction of expectations of buyers. It is the fullest $A B C$ analysis which use allows the enterprises to increase efficiency of functioning due to optimization of a product portfolio helps to reflect requirements of the market. 